\title{
Entre bastidores: etnografía de la política pública para los afrodescendientes en Cali, Colombia
}

\author{
Behind the Scenes: Ethnography of Public Policy for Afro- \\ descendants in Cali, Colombia
}

\author{
Sandra Patricia Martínez B. \\ Universidad del Valle, Colombia
}

\section{RESUMEN}

El artículo analiza el proceso de formulación de la política pública dirigida a los afrocolombianos residentes en Cali, a partir de la etnografía de las interacciones entre los actores que intervienen en su producción. Para ello, retoma la aproximación antropológica a las políticas públicas, desde la cual se plantea la necesidad de ver en ellas un proceso negociado e inserto en una compleja red de agentes, intereses y relaciones que marcan el rumbo incierto que estas pueden llegar a tomar. La etnografía, realizada en dos de los escenarios de discusión de esta política, permitió constatar la eficacia simbólica de las ceremonias públicas en tanto actos de teatralización de lo oficial, así como aproximarse a las construcciones discursivas que los actores elaboran en torno al Estado.

Palabras clave: antropología de las políticas públicas, Cali, Mesa Central de Concertación, afrodescendientes.
DOI: https://doi.org/10.22380/2539472X.577

\begin{abstract}
Based on ethnographic fieldwork this article explores the interactions between the actors involved in the production and formulation of public policy targeting the Afro-Colombians living in Cali. It draws on an anthropological approach to public policies, which proposes the need to conceptualise these as a negotiated process inserted in a complex network of agents, interests, and relations that mark the uncertain directions that these can take. Ethnography conducted in two scenarios of discussion of this policy, allows us to analyse the symbolic effectiveness of the public ceremonies as theatrical acts of the official, as well as to approach the discursive constructions through which the actors understand the state.
\end{abstract}

Keywords: Anthropology of public policy, Cali, Mesa Central de Concertación, Afrodescendants.

\footnotetext{
Doctora en Antropología Social de la Universidad Iberoamericana (Ciudad de México). Profesora del Departamento de Ciencias Sociales de la Universidad del Valle. Su última publicación es Encuentros con el Estado: burocracias y colonos en la frontera amazónica (1960-1980) (Cali: Universidad del Valle, 2017). sandra.p.martinez@correounivalle.edu.co.
} 


\section{Introducción'}

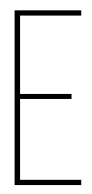

$\mathrm{n}$ los últimos veinticinco años, Colombia ha tenido un robusto desarrollo normativo a favor de las poblaciones afrodescendientes, particularmente tras la Constitución Política de 1991, en la que se las reconoció como un grupo acreedor de derechos específicos en virtud de su pertenencia étnica. Estos avances normativos se han materializado en la expedición de un buen número de disposiciones legales que, desde la Ley 70 en 1993, han ampliado el espectro de las garantías, libertades y oportunidades reconocidas a estas poblaciones, a través de la ratificación del derecho a la consulta previa, el fortalecimiento de espacios de representación política y de escenarios de concertación y planificación, el reconocimiento de la diversidad cultural y la afirmación de la identidad étnica, así como el establecimiento de instancias de apoyo a los procesos relacionados con la promoción de los derechos de la población afrocolombiana (PNUD 2010). A estas disposiciones legales se suma la amplia jurisprudencia desarrollada por la Corte Constitucional en temas como la discriminación positiva, la consulta previa, la participación de los afrocolombianos en los procesos de toma de decisiones y la protección de los derechos de las comunidades étnicas en situación de desplazamiento².

En consonancia con estos desarrollos legales, el Consejo Nacional de Política Económica y Social ha aprobado varios documentos Conpes en los que se concretan las políticas públicas relacionadas con la inclusión de la población afrocolombiana, a partir del desarrollo de las regiones con una importante presencia de esta población y de medidas orientadas a disminuir las brechas entre estos grupos y la mayoría blanco-mestiza ${ }^{3}$. Además de estos documentos, deben

1 El artículo presenta los resultados del proyecto de investigación "Etnografía de la política pública para la población afrodescendiente en Cali: actores, prácticas y representaciones", financiado por la Vicerrectoría de Investigaciones de la Universidad del Valle. Agradezco el apoyo de las estudiantes de sociología Camila Varela y Luisa María González en la realización de este trabajo.

Existen diversas interpretaciones sobre las causas del desplazamiento forzado en Colombia. Un primer conjunto de explicaciones atribuye este fenómeno a la intensificación del conflicto armado y a las acciones proferidas por los actores contendientes en contra de la población civil. Una segunda vertiente de análisis vincula el desplazamiento forzado a la pobreza, el subdesarrollo y la precaria presencia estatal. A contrapelo de estas lecturas del desplazamiento como una consecuencia, algunos autores han planteado que es una táctica de guerra empleada por los actores armados para desalojar territorios en donde existen recursos estratégicos (Pérez 2002).

3 Para mayor información sobre el contenido de estos documentos, véanse: Conpes 2909 de 1997, "Programa de apoyo para el desarrollo y reconocimiento étnico de las comunidades negras"; Conpes 3169 del 2002, "Política para la población afrocolombiana"; Conpes 3310 del 2004, "Política de acción afirmativa para la población negra o afrocolombiana"; Conpes 3660 
mencionarse los planes nacionales de desarrollo que, en sus últimas versiones, han planteado directrices tendientes a la atención de las poblaciones afrocolombianas, así como los planes formulados específicamente para ellas. Cabe señalar, sin embargo, que estos progresos no pueden verse solamente como el resultado de la iniciativa oficial. Es preciso considerar también el papel desempeñado por las organizaciones afrocolombianas en la visibilización y defensa de sus derechos.

Al tenor de los avances normativos que se han producido en el ámbito nacional sobre reconocimiento y protección de los derechos de los afrocolombianos y de la adopción de planes encaminados a la superación de sus condiciones de marginación y pobreza, las entidades territoriales con una alta presencia de estos grupos han emprendido la formulación de medidas específicas para favorecer su inclusión social. Es el caso de la Alcaldía Municipal de Cali que, en el 2007, expidió el Decreto 0634 que le dio vida a la Mesa Central de Concertación de la Política Pública para la Población Afrodescendiente del Municipio de Santiago de Cali $^{4}$. Un año después, emitió el Acuerdo 0234 del 2008, en el que se establecieron los criterios para la formulación e implementación de dicha política a partir de la puesta en marcha de acciones afirmativas dirigidas a combatir la discriminación racial y a garantizar la participación de los afrocolombianos en el diseño y ejecución de programas y proyectos en el marco de los planes de desarrollo municipal. El mismo año, el Concejo Municipal sancionó el Acuerdo 0237 del 2008, por medio del cual adoptó el Plan de Desarrollo 2008-2011, que contempló la formulación de políticas públicas con enfoque diferencial para poblaciones indígenas y afrocolombianas residentes en el municipio, el amparo de sus derechos frente a situaciones de discriminación racial, así como el fortalecimiento de la Mesa Central de Concertación. Desde entonces, los planes de desarrollo de la ciudad han incluido programas que buscan la inclusión social, económica y política de los grupos étnicos, así como aumentar sus posibilidades de acceso a los proyectos diseñados por el municipio.

del 2010, "Política para promover la igualdad de oportunidades para la población negra, afrocolombiana, palenquera y raizal".

4 La denominación de la mesa ha variado en los últimos años. En documentos institucionales más recientes, esta aparece referida como Mesa de Concertación de la Política Pública para Población Afrocolombiana, Negra, Palenquera y Raizal residente en el municipio de Santiago de Cali. Esta denominación se ajusta a las categorías que fueron utilizadas en el censo del 2005 para la clasificación de las minorías étnicas del país. En este trabajo se privilegiará el uso de los términos afrodescendiente y afrocolombiano para denominar a las poblaciones de ascendencia africana introducidas en condición de esclavitud al hoy territorio colombiano. No obstante, se conservará la palabra negro cuando aparezca en los documentos oficiales o en el discurso de los actores. 
Ahora bien, la adopción de estas medidas en una ciudad como Cali no es, en modo alguno, gratuita. Cali no solo es la ciudad colombiana que en términos absolutos concentra el mayor número de afrodescendientes, con 554.568 personas (DANE 2005) $)^{5}$, sino que además es el escenario de profundas desigualdades étnico-raciales. Los principales indicadores sociodemográficos muestran las condiciones de vulnerabilidad demográfica en las que se encuentran las poblaciones afrodescendientes en relación con los demás grupos étnicos, así como la alta incidencia de fenómenos como el desplazamiento forzado en su precariedad social y económica. Al mismo tiempo, los indicadores de calidad de vida evidencian el acceso restringido de estas poblaciones a más y mejores oportunidades de vida, lo que se expresa no solamente en los altos niveles de necesidades básicas insatisfechas, sino también en los deficitarios servicios de vivienda, salud y educación que reciben. Los datos relativos a la participación de la población afrocolombiana en el mercado de trabajo muestran la persistencia de profundas brechas étnico-raciales en la calidad del empleo, los niveles de remuneración y, en general, las condiciones de inserción ocupacional que restringen sus posibilidades de movilidad social ascendente y alimentan el ciclo intergeneracional de desventajas acumulativas (Cidse y ACDI VOCA 2016).

No obstante esta apremiante situación y la existencia desde hace una década de los mecanismos legales necesarios para viabilizar la formulación de una política pública para los afrocolombianos residentes en Cali, aún no se cuenta con un documento que recoja el consenso entre las organizaciones y las entidades oficiales en torno a dicha política. El funcionamiento de la mesa ha sido intermitente durante estos diez años, con largos periodos de receso en algunas administraciones y otros de intensa discusión en torno a la manera de llevar a la práctica lo preceptuado en el Acuerdo 0234 del 2008. Pero, más allá de una evaluación del "éxito" o “fracaso" en el logro del propósito de construir dicha política pública, lo que interesa analizar en este artículo es el proceso mismo de su diseño, en términos de las configuraciones específicas de actores, actividades e influencias que intervienen en su producción. Así, a partir de la etnografía de las interacciones que se producen entre los actores que participan en este proceso,

5 De acuerdo con el censo del 2005, 4.311.757 personas en el país se reconocieron como afrocolombianas, lo que equivale al 10,62\% del total nacional. En Cali y su área metropolitana se concentra la mayor cantidad de población afrodescendiente con 823.920 personas, superando incluso el número de los que residen en las cabeceras de los 50 municipios del andén Pacífico (643.559 personas) (DANE 2005). Según estimativos de la Cepal, la OPS y el UNFPA (2017), después de Brasil, en donde viven 97.171.614 afrodescendientes, Colombia cuenta con la población afrodescendiente más grande de América Latina. 
se examinará la formulación de la política pública de la Alcaldía de Cali para las poblaciones afrodescendientes.

La etnografía de las políticas públicas constituye un camino privilegiado para acceder a la manera en que el Estado intenta cristalizarse en la vida cotidiana de los individuos. La consideración de este como un proceso inacabado que se cimenta en las prácticas y representaciones surgidas en la interacción entre las burocracias y los ciudadanos (Gupta 1995; Gupta y Sharma 2006; Nuijten 2003; Trouillot 2001) trae a primer plano el análisis del "Estado imaginado", esto es, de los mecanismos o modalidades mediante los cuales unas y otros lo construyen discursivamente. Esta perspectiva permite aproximarse no solo a las lecturas e interpretaciones que los actores elaboran del Estado y a la manera como estas producciones discursivas ordenan las formas de interacción entre ellos, sino también a las diversas atribuciones causales que estos suelen otorgarle, en las que las acusaciones en contra del aparato estatal como el culpable de sus fracasos e infortunios coexisten con las invocaciones de una mayor presencia de este. Anclada en métodos empíricos de investigación, la antropología del Estado sugiere que las dicotomías convencionales entre el Estado y la sociedad civil, lo público y lo privado, el Gobierno y el mercado, la coerción y el consenso, la soberanía y la autonomía, lo global y lo local, lo macro y lo micro, lo centralizado y lo descentralizado - entre otras-no permiten comprender las expresiones contemporáneas del poder político (Abrams 1988; Aretxaga 2003; Gupta 1995; Gupta y Sharma 2006). Este trabajo se servirá además de algunas nociones acuñadas por Bourdieu, cuyos planteamientos, si bien no pueden enmarcarse estrictamente dentro de esta línea de análisis, aportan pistas valiosas para entender cómo se reproduce la autoridad del Estado a través de diversos símbolos y ritos institucionales.

Bajo el alero de esta perspectiva analítica, desde la década de los ochenta del siglo anterior el estudio de las políticas públicas empieza a ganar un creciente interés en el campo de la antropología política. A partir del cuestionamiento a la consideración de las políticas como una secuencia lógica de pasos lineales (formulación, implementación, evaluación), los autores afines a este enfoque llaman la atención sobre la necesidad de ver en ellas un proceso negociado en el que los actores involucrados ponen en juego diversas lógicas e intereses, afectando de esta manera los resultados alcanzados. Lejos de seguir un proceso lineal con efectos predeterminados, las políticas públicas se insertan en una compleja red de agentes, intereses y relaciones que marcan el rumbo incierto que estas pueden llegar a tomar (Murray Li 2007; Shore 2010; Shore y Wright 1997; Wedel et al. 2005). Es justamente esta constelación de actores, operaciones y relaciones lo que la antropología de las políticas públicas se propone develar. 
Entendiendo el proceso de formulación de políticas públicas como el conjunto de prácticas y formas organizacionales que les dan vida a las políticas (Shore 2010), esta perspectiva se interesa por lo que hacen y piensan quienes las diseñan, lo que implica un esfuerzo por esclarecer la manera en que los formuladores de políticas crean sentido y las prácticas culturales que sostienen sus sistemas de pensamiento. A continuación, se exponen los principales resultados de la observación participante realizada en dos de los escenarios de discusión de la política: las reuniones de la Mesa Central de Concertación, que tuvieron lugar el segundo semestre del 2016, y la Asamblea de Organizaciones Afrocolombianas del Municipio de Santiago de Cali, realizada a finales del 2016. Cabe precisar que mi asistencia a dichos escenarios se produjo en calidad de delegada de la institución educativa en la que trabajo, que, junto con otras entidades descentralizadas, tiene asiento en la mesa y participa en las decisiones de este organismo con voz y voto.

\section{Mesa Central de Concertación: las performances de la política pública}

Pensada como un mecanismo de interlocución entre los afrodescendientes y las entidades oficiales del orden municipal, la Mesa Central de Concertación es un espacio mixto del que hacen parte nueve delegados de estas organizaciones, y cada uno representa un "eje temático" o frente de trabajo (salud y supervivencia; vivienda, medio ambiente y territorio; cultura, recreación y deporte; generación de ingresos y empleo; legislación y derechos humanos; comunicación, información y tecnología, y género y generación). A la mesa también asisten once funcionarios de la Alcaldía (ocho de ellos pertenecientes a las secretarías municipales) y siete de otras entidades del nivel local, dos de ellas adscritas al Ministerio Público y las restantes relacionadas con el sector educativo, la atención a la infancia y la producción de estadísticas (Decreto 0634 del 2007). De manera paralela, funciona el llamado "espacio autónomo", en el que los delegados afrodescendientes se reúnen con las organizaciones para recoger sus demandas y propuestas, que luego son presentadas en las reuniones de la mesa en pleno.

La mesa tiene como escenografía el salón de gobierno de la Alcaldía, y en la citación y realización de las reuniones sigue de manera más o menos rigurosa una serie de rituales burocráticos que buscan reforzar el carácter oficial de estos encuentros: envío de una convocatoria a los delegados por parte de la Secretaría de Bienestar, fijación de un orden del día y verificación del quorum al inicio de 
cada reunión. Desde la primera reunión a la que asistí, me percaté de la riqueza de este escenario para observar las interacciones reales que surgen entre las burocracias del nivel local y los ciudadanos, representados en este caso en los delegados de las poblaciones afrocolombianas. Llegué a este espacio en un momento coyuntural en el que se hacía necesaria la elección de nuevos delegados de las organizaciones, dado el vencimiento del periodo para el cual habían sido electos sus voceros. El alcalde de la ciudad, elegido para ocupar este cargo entre el 2016 y el 2019, se había comprometido ante el Concejo Municipal a renovar la composición de la mesa dentro de los primeros cien días de su gobierno, con el propósito, a mediano plazo, de poner en marcha la política pública para los afrodescendientes. En cumplimiento de este mandato, en junio del 2016, la Secretaría de Bienestar Social - dependencia de la Alcaldía de Cali, a cargo de la secretaría técnica de la mesa - había expedido una resolución que establecía, para mediados de ese mismo mes, la realización de la asamblea en la que se elegirían los nuevos dignatarios. Sin embargo, esta disposición había sido revocada mediante un recurso legal interpuesto por los delegados afrodescendientes, quienes solicitaron la ampliación del plazo para la celebración de dicha asamblea.

La dinámica de las reuniones durante el segundo semestre del 2016 estuvo pautada por la confrontación entre los delegatarios de las organizaciones y los funcionarios de la Secretaría de Bienestar. Después de los actos protocolarios de rigor, verificación del quorum y lectura de los actos administrativos que reglamentan el funcionamiento de la mesa, las discusiones giraron en torno al estancamiento del proceso de formulación de la política pública. Los representantes de las organizaciones, siempre poniendo de presente su adhesión a las instituciones y las normas, alegaban la falta de "voluntad política" de las distintas administraciones municipales para avanzar en la construcción de la política, y señalaban el manejo de un "doble discurso" por parte de los alcaldes, que en los escenarios públicos pregonan el afecto hacia las poblaciones afrodescendientes pero que en la práctica no hacen cumplir sus derechos. Así lo expresó uno de los delegados:

La mesa ha hecho mucho, pero nunca ha sido tenida en cuenta en Cali, lo que hemos hecho es con nuestros propios recursos. No hemos venido a pedirle nada a nadie, simplemente que nos reconozcan una igualdad real. Como abogado planteo que los negros de Cali hemos sido muy complacientes, hemos querido apoyar a un alcalde que se ha preocupado por los negros, porque Guerrero y Ospina nunca se preocuparon por nosotros. ${ }^{6}$

6 Intervención de un delegado afrocolombiano en la reunión de la Mesa Central de Concertación, Cali, 7 de julio del 2016. 
En la misma dirección, los delegados afrodescendientes manifestaban la falta de compromiso de los funcionarios de la Administración Municipal frente al cumplimiento de la normatividad que protege a estas poblaciones, argumentando que en algunos casos desconocen dichas normas, en otros son renuentes a la aplicación del enfoque diferencial y en otros tienen "agendas ocultas”. En su opinión, estos últimos pretenden utilizar el escenario de la mesa para favorecer intereses políticos particulares. La declaración de uno de los delegados no puede ser más explícita:

Entre los funcionarios, está haciendo carrera una actitud de "salir del paso". El tema de la convocatoria [a la asamblea] es un tema mínimo frente a la política pública. Hay un interés de instrumentalizar el espacio de la mesa. La mesa tiene que seguir, es lo único que los negros tenemos para mostrar en Cali. ${ }^{7}$

Los líderes también denunciaban actitudes discriminatorias por parte de los servidores públicos hacia los delegados afrodescendientes que se habían acercado a sus oficinas para realizar consultas o trámites: "Queremos que los funcionarios entiendan que no es un favor. Cuando uno es funcionario, uno se debe al pueblo, ¿cómo así que no reciben a nadie? Y discriminan a la gente, ¡huele a asco!, ihuele a chucha!"». De igual forma, fue recurrente la defensa del "espacio autónomo" como instancia encargada de definir los criterios para la elección de los nuevos dignatarios, establecer el modus operandi de la asamblea de delegados y fijar la fecha para su realización ${ }^{9}$. La inasistencia del alcalde y de los secretarios de despacho a las reuniones de la mesa era una de las reclamaciones más reiteradas. Sobre este aspecto volveré más adelante.

Por su parte, los funcionarios de la Secretaría de Bienestar expresaban su preocupación por el retraso en el proceso de renovación de los delegados de la sociedad civil, cuyo periodo de representación se había vencido dos años atrás. La elección de los nuevos dignatarios no había sido posible, en parte por la

7 Intervención de un delegado afrocolombiano en la reunión de la Mesa Central de Concertación, Cali, 21 de julio del 2016.

8 En Colombia la palabra chucha es utilizada para referirse al mal olor de las axilas.

9 En su etnografía sobre los movimientos afrocolombianos, Asher ([2009] 2016) registra la ocurrencia de una situación similar en la asamblea pública convocada por la Corporación Autónoma Regional del Valle del Cauca (CVC) para la elección de un representante de las comunidades afrodescendientes al Consejo Directivo de la Corporación. En esta asamblea, los integrantes del Proceso de Comunidades Negras (PCN) impugnaron la agenda propuesta por los funcionarios de la CVC y reclamaron la participación de las organizaciones, tanto en la construcción de la agenda como en la definición del procedimiento para la elección del representante. 
inactividad de la mesa durante un largo periodo, pero también debido a varias solicitudes de aplazamiento presentadas por los delegatarios afrodescendientes mediante distintos recursos legales que, a los ojos de algunos funcionarios, se constituían en una estrategia para asegurar su permanencia en la mesa y, con ella, el acceso a ciertos réditos políticos y económicos. Frente a la constante apelación de los líderes al "espacio autónomo", los funcionarios invocaban una y otra vez el Decreto 0634 del 2007, que establece que la Mesa Central de Concertación es un espacio mixto conformado tanto por delegados de las organizaciones como de las entidades oficiales. La exigencia de los representantes afrodescendientes era vista por los funcionarios como una manera de eludir la veeduría institucional durante el proceso de toma de decisiones. En opinión de una delegada, los voceros de las organizaciones "le juegan a la fatiga de las instituciones, pero lo importante es no dejarse fatigar”.

Los funcionarios de las otras dependencias e instituciones que en todos los casos asistieron a las reuniones en calidad de delegados no disimulaban su incomodidad frente a la dinámica que estas habían adquirido y reaccionaban de distintas maneras ante la situación: se retiraban del recinto, solicitaban la cancelación de las reuniones, interpelaban a los representantes de las organizaciones por retrasar la realización de la asamblea o por desconocer las facultades de las que, como empleados públicos, habían sido investidos para participar en las sesiones. Al respecto, una funcionaria opinó:

He asistido a varias reuniones y todas se han levantado o por falta de quorum o porque solo vienen los delegados. Hay mucha discusión, pero no se llega a acciones concretas. No me interesa si hay "agendas ocultas”, la elección de los delegados se hace de manera autónoma. Es muy incómodo para uno estar en esta discusión. ${ }^{10}$

Finalmente, después de varias reuniones que terminaron sin llegar a ningún acuerdo respecto al proceso de elección de los nuevos delegados, se aprobó la fecha propuesta por los líderes para la realización de la asamblea ${ }^{11}$.

Las declaraciones expresadas en las reuniones de la mesa plantean algunas reflexiones de interés para los propósitos de este trabajo. En un sentido importante, este escenario podría ser pensado a la luz del concepto bourdiano de

10 Intervención de una funcionaria en la reunión de la Mesa Central de Concertación, Cali, 21 de julio del 2016.

11 Al respecto, Asher ([2009] 2016) menciona los sentimientos de frustración e impaciencia de los funcionarios estatales frente a las lógicas de discusión que caracterizan los espacios de diálogo con las poblaciones afrodescendientes, en los que cada tema es objeto de largos debates que, en muchos casos, concluyen sin llegar a acuerdos concretos. 
comisión (Bourdieu 2014), aquella invención organizativa del Estado en la que un grupo de personas consideradas habilitadas son designadas para tratar un problema público; en este caso particular, los funcionarios de las instituciones concernidas en la atención a las poblaciones afrodescendientes y los delegados de las organizaciones, reunidos para discutir la formulación de la política pública dirigida a estas poblaciones. En tanto actos de teatralización de lo oficial, las comisiones suponen una escenografía que busca generar efectos simbólicos de conformidad con las verdades oficiales y, de este modo, proyectan una visión legítima de un problema público. La verdad oficial aquí defendida por los héroes burocráticos - para utilizar la expresión bourdiana- es que la actual Administración Municipal está comprometida con la política pública para los afrodescendientes, que el alcalde está dispuesto a "quebrarle el espinazo a la marginalidad" a través de políticas de inclusión social, como lo señalara uno de los funcionarios, y que es preciso disminuir la brecha existente entre ellos y los demás grupos étnico-raciales con presencia en la ciudad ${ }^{12}$. En este acto de teatralización, los funcionarios cumplen su papel como voceros de "lo oficial", apelando a uno de los lenguajes de la estatalidad por excelencia: el jurídico. Es así como, en las intervenciones que hacen en cada reunión, casi siempre se apoyan en la lectura o citación de los decretos y acuerdos que reglamentan el funcionamiento de la mesa, así como del Plan de Desarrollo vigente.

Que los funcionarios recurran al lenguaje estatal es algo que quizá parezca natural, pero que los delegatarios de las organizaciones lo hagan, y la insistencia con la que lo hacen, es algo que merece una reflexión sobre la manera en que los individuos incorporan las categorías de pensamiento en las que se sostiene la dominación política estatal (Bourdieu 1994). Incluso aquellos que dicen oponerse al orden establecido terminan adoptando, en sus expresiones y estrategias de resistencia, las formas y lenguajes de la estatalidad para poder interactuar con el orden oficial (Roseberry 1994). Es así como en sus intervenciones los delegados afrodescendientes son enfáticos en señalar que se acogen a los procedimientos legales y que reconocen la autoridad de las instituciones públicas, además de citar las normas jurídicas y las actas en las que se sustentan los acuerdos previamente establecidos. El pronunciamiento de uno de los líderes es ilustrativo en este punto:

No estamos esperando que se nos regale nada, sino la construcción de una ciudad incluyente, que los funcionarios asuman su responsabilidad

\footnotetext{
12 Para el año 2005 se censaron en Cali 2.075 .380 habitantes, de los cuales el 0,5\% se autorreconocieron como indígenas, el $26,2 \%$ como afrodescendientes y el $73 \%$ como población no étnica o blanca-mestiza (DANE 2005).
} 
y que sepan que existe un marco normativo y legal. Reconocemos la institucionalidad, la jerarquía de las normas, pero nos vamos a valer de esos mecanismos para hacer valer nuestros derechos. ${ }^{13}$

Asimismo, en su interacción con los funcionarios de la Alcaldía, los representantes de las organizaciones han adquirido cierto nivel de competencia en el uso de los instrumentos jurídicos disponibles para solicitar información, denunciar la violación de derechos fundamentales o solicitar la revocatoria de los actos administrativos expedidos por la Administración Municipal. La recurrencia de este hecho, que ha sido identificado en investigaciones desarrolladas en otras regiones del país y de América Latina ${ }^{14}$, podría estar indicando que, a contrapelo de la socorrida “ausencia del Estado”, lo que hay es un exceso de prácticas de estatalidad, es decir, muchos actores compitiendo por representarse como Estado (Aretxaga 2003).

Además de la adopción de las prácticas y lenguajes de la estatalidad, la eficacia simbólica de esta ceremonia pública que representa la mesa se comprueba al escuchar el insistente reclamo de líderes para que en las reuniones estén presentes quienes ejercen la titularidad de los cargos en las instituciones que tienen asiento en ella (alcalde, secretarios de despacho, directores) y no sus delegados, por considerar que estos últimos no tienen la potestad de tomar las decisiones que requieren ser discutidas en dicho escenario. “¿Por qué no está el alcalde, ni el secretario de Desarrollo Territorial, que son quienes toman las decisiones?”, se pregunta uno de los líderes. Y después agrega: "Esto indica que no hay cambio, nos hemos vuelto ‘discurseros', manejamos un doble discurso”15.

Siguiendo con Bourdieu, la importancia concedida a estas titularidades podría ser interpretada como un resultado del efecto de consagración producido por la investidura, que como tantos otros ritos de institución tiene el poder de “actuar sobre lo real actuando sobre la representación de lo real” $(1993,116)$, Cali, 7 de julio del 2016.

Véanse las investigaciones de Torres $(2006,2007)$ entre los colonos del Putumayo; de Chaves y Hoyos (2011), con los indígenas del mismo departamento; de Bolívar (2006), sobre los campesinos en el Magdalena Medio; de Asher ([2009] 2016), respecto a los movimientos sociales de las poblaciones afrodescendientes en el Pacífico colombiano, y de Lagos (2008) acerca de las formas de movilización campesina en una provincia boliviana.

Otros académicos han llegado a resultados similares al encontrar que los pobladores prefieren negociar con funcionarios de alto rango, pues estiman que de esta manera sus solicitudes tendrán una mayor resonancia. Al respecto, véanse los estudios de Ramírez (2001) sobre las marchas cocaleras en el Putumayo, de Nuijten (2003) acerca de los ejidatarios mexicanos, de Bolívar (2006) respecto a los campesinos del Magdalena Medio, y de Lazar (2008) sobre las negociaciones entre las pescaderas y las burocracias bolivianas. 
es decir, de sancionar y santificar diferencias en las posiciones que los actores ocupan en el espacio social, en este caso, mediante el nombramiento en cargos públicos. Así, la eficacia simbólica de la investidura descansa, por un lado, en el reconocimiento que la persona consagrada recibe de los demás, quienes le otorgan un tratamiento de respeto en virtud de su posición y, por el otro, en la imagen que esta persona se forja de sí misma y en los comportamientos que debe adoptar en consonancia con esa imagen.

Ahora bien, pese a las diferencias aparentemente irreconciliables entre los delegados de la sociedad civil y los de las instituciones, las fronteras que separan a unos y otros no son tan nítidas como pudiera pensarse a primera vista. De hecho, todos los funcionarios de la oficina a cargo del tema de las poblaciones afrodescendientes en la Secretaría de Bienestar pertenecen a este grupo étnico, al igual que una buena parte de los delegatarios de las demás dependencias e instituciones que integran la Mesa Central de Concertación, lo que evidencia la vinculación cada vez mayor de personas de origen afrodescendiente a la administración pública. Algunos han participado o participan actualmente en procesos organizativos étnicos, e incluso uno de ellos fue delegado de estas organizaciones en la mesa. Pero, más allá de este hecho, es importante hacer notar la autoconsciencia que estas personas expresan sobre su doble condición como funcionarios y como afrocolombianos, y lo que esto significa para ellos en el trabajo que desarrollan con dichas poblaciones. El testimonio de un funcionario de la Secretaría de Bienestar es diciente:

A mí me motiva el tema porque lo he vivido ¿sí?, o sea, yo he vivido la pobreza extrema, he vivido la discriminación y me han ocurrido acontecimientos que han marcado, digamos, tomar una posición en la vida, ¿cierto?, de luchar por los derechos humanos y de luchar contra la discriminación racial, entonces, eso me ha motivado a estudiar derecho y a ser la persona que [soy] hoy, digamos, de alguna manera avanzo conforme a lo que pienso y a lo que digo. ${ }^{16}$

Situados en una posición ambigua, algunos de estos funcionarios asumen ciertas posturas críticas frente a la manera en que los delegados han llevado a cabo la representación de las organizaciones en la mesa, así como respecto a las prácticas políticas de sus congéneres, al tiempo que manifiestan su solidaridad con el "pueblo" afrocolombiano. Así lo demuestran las sentidas palabras de una funcionaria preocupada por los magros avances del proceso de formulación de la política: “Gran parte de los que estamos aquí somos 'afro', nosotros también 
somos comunidad y ¿dónde queda mi responsabilidad con mi comunidad? ¿Con mi familia?”. Esta circunstancia confirma una vez más el carácter poroso de las fronteras entre el Estado y la sociedad civil, tan ampliamente discutido en la literatura de la antropología del Estado referida, pero también en la producción académica latinoamericana inspirada en este enfoque (Bolívar 2010; Canelo 2008; Herron 2003; Martínez 2015; Ramírez 2001).

En relación con las construcciones discursivas que los actores elaboran en torno al Estado, si bien este no es mencionado explícitamente en los discursos de los delegatarios, su presencia es invocada de distintas maneras: en el caso de los voceros de las organizaciones, a través de la alusión a la Administración Municipal y al modus operandi de los funcionarios, y de forma más sutil, mediante el reconocimiento que hacen de las normas y de la institucionalidad; en el caso de los delegados estatales, por medio de la constante apelación a las disposiciones legales y del acatamiento de los procedimientos oficiales. Como se pudo ver en el recuento de las reuniones de la mesa, la relación entre los representantes afrodescendientes y la Alcaldía —en tanto expresión local del aparato estatal- está mediada por la desconfianza en la imparcialidad y en la justeza de esta institución. Al respecto, algunos autores han señalado que los ciudadanos construyen “teorías conspiratorias” para explicar la falta de éxito en la consecución de sus objetivos cuando negocian con las instancias oficiales, especialmente en situaciones conflictivas rodeadas por una atmósfera de opacidad e inseguridad (Hansen y Stepputat 2001; Herzfeld 1997, 2005; Nuijten 2003). Este es el caso de los líderes afrodescendientes, quienes permanentemente aluden a la falta de "voluntad política” de la Administración Municipal para materializar los derechos reconocidos a estas poblaciones, señalando la indiferencia con la que algunos alcaldes han tratado este tema, al no contemplar la inclusión de políticas de atención diferencial en sus planes de desarrollo ni convocar el espacio de la mesa para discutir la formulación de la política pública. Con gran indignación, los líderes culpan a los mandatarios de instrumentalizar al "pueblo" afrocolombiano que es evocado en los periodos de elecciones o para "vender" una imagen positiva de su gobierno ante los medios de comunicación, pero que no es tenido en cuenta dentro de las políticas de desarrollo para la ciudad. A estas diatribas, se suman los señalamientos en contra de algunos de los funcionarios de la Alcaldía a cargo del tema, acusados de tener "agendas ocultas" que encubren intereses políticos y económicos particulares. Así, refiriéndose al espacio de la mesa, uno de los delegados expresó: "Esto se ha vuelto un botín de vulgar politiquería barata que está buscando posicionar una agenda oculta”. A juicio de los líderes, algunos servidores públicos discriminan a los afrocolombianos mientras que otros ven el enfoque diferencial 
como una "entelequia", de tal suerte que no reconocen la legitimidad de la Mesa Central de Concertación. En palabras de uno de ellos: "cuando acudimos a las oficinas de los funcionarios, nos encontramos con las mismas dificultades: no hay presupuesto o [nos dicen] “¿por qué debo tratar con preferencia a una población, si según la Constitución debo tratarlos a todos por igual?”.

\section{Asamblea de Organizaciones Afrocolombianas y taxonomías burocráticas}

En la introducción de este artículo se planteó que uno de los aspectos que la antropología de las políticas públicas se propone develar son las visiones de mundo que los formuladores de política buscan sostener y cómo estas condicionan sus decisiones y formas de interacción con el público al cual dirigen sus acciones (Shore 2010; Wedel et al. 2005). En una dirección similar, algunos autores han señalado que gran parte del trabajo burocrático se enfoca en la creación y aplicación de taxonomías, es decir, principios de clasificación y categorización de la población que tienen como resultado la inclusión de algunos sectores en detrimento de otros. Para dichos autores las burocracias son, ante todo, instrumentos de poder que, mediante estos esquemas taxonómicos, logran una mayor legibilidad de la población, y con ello un control más efectivo de esta (Handelman 1981; Heyman 2004).

Sin llevar su argumento tan lejos, Fassin (2015) ha insistido en el papel que desempeñan los valores y afectos profesados por las burocracias, en la manera en que ellas responden a sus obligaciones y en el comportamiento que adoptan frente a los ciudadanos. Son justamente estos sistemas de valores y principios éticos sobre el bien y el mal, la justicia o la injusticia, la legalidad y la ilegalidad - por mencionar apenas algunos de ellos- el prisma a través del cual evalúan determinadas conductas, culpan o estigmatizan a ciertas poblaciones, expresan suspicacia hacia otras o victimizan a ciertos grupos, asumiendo actitudes de adhesión, adaptación o rechazo en su interacción cotidiana con ellos. Así, lejos del prototipo weberiano del funcionario desapasionado que rige su conducta con atención rigurosa a los estatutos objetivos del cargo, haciendo de la eliminación del amor, el odio y la irracionalidad su máxima virtud (Weber [1922] 1977), las burocracias se encuentran profundamente permeadas por los discursos que circulan en el debate público acerca de las poblaciones con las cuales desarrollan su trabajo. 
En la Asamblea de las Organizaciones Afrocolombianas para la elección de los delegados a la mesa, tuve la posibilidad de conocer más de cerca las construcciones discursivas que los funcionarios elaboran en torno al comportamiento político de estas poblaciones. Pero antes quisiera detenerme en la dinámica de esa asamblea en particular, pues puede ayudar a comprender el contexto de enunciación de los puntos de vista expresados por los agentes oficiales.

El orden del día propuesto por la Secretaría de Bienestar contemplaba la realización de cinco actividades: acto protocolario de instalación, informe de la Secretaría de Bienestar Social, explicación de la metodología de trabajo, elección de los delegados para integrar los nueve ejes temáticos y plenaria de socialización de los resultados de las mesas de trabajo y designación de delegados. Las dos primeras se desarrollaron sin contratiempos, pero una vez los funcionarios de la Secretaría procedieron a explicar la metodología, consistente en la conformación de nueve mesas de trabajo de acuerdo con los ejes temáticos contemplados en el Decreto 0634 del 2007, reglamentario del funcionamiento de la mesa, se encontraron con la resistencia de los asistentes, quienes reivindicaban la autonomía de las organizaciones para establecer el procedimiento a seguir en la elección de los delegados. Ante esta situación, uno de los funcionarios de la Secretaría de Bienestar hizo un llamado a no convertir la asamblea en un espacio político, lo que inmediatamente generó la airada reacción de una lideresa que, prolijamente ataviada con un turbante y una manta que rememoraban su origen africano, exclamó en medio de los aplausos del público: “este sí es un espacio político, aquí vamos a avalar y a refrendar a quien nos va a representar”. Por solicitud de los asistentes, los funcionarios de la Secretaría tuvieron que retirarse de la asamblea, no así el veedor del Ministerio Público ni las otras delegadas que nos encontrábamos allí en calidad de observadoras.

Después de designar a las personas que fungirían como presidente, secretaria y moderador de la asamblea, se sometió a votación el mecanismo para la elección de los delegados. Aunque un buen número de los asistentes votó a favor del sistema de planchas, esta elección fue cuestionada por otras personas que expresaban su inconformidad frente a la dinámica que se generó, en la que se formaron grupos para ponerse de acuerdo en los nombres que integrarían las listas de cada plancha. Además del desorden causado por dicha situación, estos objetaban que el sistema de planchas suponía la exclusión de aquellos líderes que, siguiendo las directrices de la Secretaría de Bienestar, se habían postulado de manera individual a los nueve ejes temáticos. Las palabras de una lideresa muestran el rechazo de una buena parte de los asambleístas a esta manera de proceder:

[...] entonces, por favor, hago un llamado de reflexión frente a mi posición de representación, que en el momento los que queden en la mesa no 
se olviden y simplemente nada más se basen en representar a su conveniencia, a su antojo, entonces que nos quedemos por fuera la gente que realmente estamos necesitados en esos sitios, excluidos, que no tenemos derecho a nada, entonces sí hago ese llamado de reflexión para que de aquí en adelante lo que pase hayamos gente responsables en defender unos derechos colectivos. ${ }^{17}$

Con el fin de posibilitar la participación de un mayor número de personas en la mesa, uno de los asistentes propuso que se creara la figura de las suplencias para cada una de las delegaciones principales y que la plancha que obtuviera la votación más alta asumiera cinco de las delegaturas. Aquella que ocupara el segundo lugar en la votación, tomaría las cuatro restantes. Finalmente, la propuesta fue acogida con una ligera variación: a la plancha ganadora se le adjudicarían cinco designaciones principales y cuatro suplencias, mientras que a la plancha que le siguiera se le asignarían cuatro escaños principales y cinco suplencias.

Posteriormente, se abrió un espacio para que los asistentes acordaran los nombres que incluirían en cada plancha. Después de un rato se anunciaron los integrantes de cada lista, entre los cuales fueron mencionados tres de los delegados salientes. Este anuncio generó una nueva controversia entre algunos que se opusieron a la reelección de dichos delegados. Pese a este desacuerdo, se procedió a la votación de las planchas, cuyos resultados evidenciaron la amplia favorabilidad hacia una de las listas, que obtuvo exactamente el doble de los votos alcanzados por la segunda (76 y 38 votos, respectivamente). Una vez efectuada la elección, la presidente de la asamblea dio a conocer los nombres de las personas designadas para integrar la mesa y les solicitó a los funcionarios de la Secretaría de Bienestar que se reintegraran a la reunión para verificar el listado de elegidos.

Durante esta jornada, en la que me senté al lado de otras delegadas de las instituciones - algunas de ellas afrocolombianas-que asistieron en calidad de espectadoras, tuve la oportunidad de conocer sus impresiones sobre lo que acontecía. Un primer aspecto que apareció de manera recurrente fue el cuestionamiento de las funcionarias a las formas de ejercicio de lo político entre los afrodescendientes. Ellas no disimulaban su incomodidad frente al desorden en medio del cual se desarrollaba la asamblea, pues a pesar de la designación de un moderador y de una presidente para dirigir la reunión, el público no guardaba silencio, algunas personas se tomaban la palabra, mientras otras se distraían en los grupos sin prestar atención al "orden” que el moderador infructuosamente trataba de establecer. A juicio de las funcionarias, el caos que suele reinar en los

17 Intervención de una lideresa en la Asamblea de Organizaciones Afrocolombianas, Cali, 26 de noviembre del 2016. 
escenarios de debate público en los que se abordan temas relacionados con las poblaciones afrodescendientes obedece a la dificultad que estas enfrentan a la hora de sujetarse a la autoridad de otros, lo que, en opinión de una de ellas, puede explicarse en virtud de la baja autoestima ocasionada por el atávico sometimiento del que han sido objeto:

[...] por eso es que a la población afro le dan tratamiento de quinta categoría, porque nuestra etnia tiene dificultades para dejarse orientar, tiene problemas de jerarquía, de una autoestima baja, que todo lo ven como que se está mandando, que se les está imponiendo algo, entonces la capacidad de liderazgo, cualquiera que la tenga se la tratan de disminuir. ${ }^{18}$

Este hecho, que la funcionaria explica en términos de la baja autoestima de los afrodescendientes, fue registrado por Wade (1997) en su estudio sobre las identidades raciales en Colombia, en el que acuña la noción de ética de la igualdad para explicar el sentido de solidaridad esencial que subsiste entre los chocoanos, quienes, al reconocerse como parte de una colectividad en la que "todos son iguales”, enfrentan dificultades para tolerar las jerarquías. Así, quienes logran ascender en la escala social, ya sea mediante el mejoramiento de su estatus económico, de su nivel educativo o de su prestigio político, pasarán a ser objeto de estricta vigilancia: cualquier negativa a las solicitudes de ayuda de sus paisanos o cualquier comportamiento que no cumpla con las expectativas del grupo serán sancionados por sus congéneres y los acusados enfrentarán toda suerte de señalamientos, cuando no el ostracismo y el rechazo sociales. Esta noción ha sido retomada por autores como Agudelo (2005) quien, en su trabajo sobre el comportamiento político de las poblaciones afrocolombianas, encontró que la "ética de la igualdad" ha implicado un bloqueo al surgimiento de ciertos liderazgos que, al demostrar habilidades para competir en la arena electoral, amenazan la solidaridad étnica. En una dirección similar, Hoffmann (2007) se sirvió de este concepto para explicar los mecanismos de regulación que los habitantes de los caseríos ribereños tumaqueños ejercen para contrarrestar la acumulación de capital político por parte de algunos individuos.

No menos interesante es la comparación con la dinámica organizativa indígena ${ }^{19}$. A la manera de un "efecto reflejo", los funcionarios valoran las formas

Conversación informal con la delegada de una institución, Cali, 26 de noviembre del 2016.

En el preámbulo del estudio sobre el Movimiento Social Afrocolombiano publicado por la Universidad Nacional de Colombia en el 2012, Wabgou señala que persiste una tendencia entre los activistas y los académicos a comparar este movimiento con los procesos organizativos indígenas más consolidados, con lo cual se desconoce no solo la diversidad que subsiste en su interior, sino también las trayectorias específicas que han tenido los afrocolombianos, negros, palenqueros y raizales en sus procesos de articulación a la nación (Wabgou et al. 2012). 
de participación de los afrodescendientes a la luz del espejo de lo indio y resaltan el orden imperante en los espacios de concertación a los que son convocados los indígenas, que atribuyen a la disciplina y el respeto que profesan hacia sus autoridades, así como al nivel de cohesión existente entre ellos. En palabras de una de las delegadas: "Mire en los indígenas, mire para hacer consenso, mire ellos cómo son de juiciosos, yo he ido a cabildos, yo me he quedado boquiabierta, hasta la comida... toda la comida alcanza para todos, es una cosa impresionante”. Aunque este tipo de discursos apareció de manera reiterada en la asamblea y en las reuniones de la mesa, algunos funcionarios cuestionan el comunitarismo atribuido a los indígenas. Así, por ejemplo, una de las delegadas se refirió al disgusto que le causó escuchar la siguiente expresión: “iqué peligro un negro con poder!”. Además de su indignación frente a la connotación racista de estas palabras, la funcionaria argumentó que el abuso de autoridad de quienes se encuentran en situación de ejercer el dominio sobre otros no está asociado necesariamente al color de la piel, y sustentó su afirmación en algunos casos de corrupción que se han presentado en el seno de los partidos políticos indígenas.

El proceso de elección que estábamos presenciando nos condujo, casi que de manera inevitable, a la reflexión sobre las prácticas políticas de los afrocolombianos. Como se mencionó, aunque el sistema de planchas terminó por imponerse sobre los otros mecanismos de elección, no pocos asistentes refutaron este sistema por considerar que terminaba excluyendo a los representantes de las organizaciones que se habían postulado individualmente, es decir, que no habían establecido alianzas previas con otros sectores, como también a aquellos líderes más jóvenes, que no cuentan todavía con una larga trayectoria en los procesos organizativos. Las palabras de uno de los asambleístas evidencian esta situación:

Bueno, compañeros, yo no sé la gran mayoría de los que hay aquí, yo creo que la gran mayoría son nuevos en el proceso, ¿cierto? Levanten la mano los nuevos. Bueno, muy bien, pues resulta que los nuevos estamos en un proceso de exclusión de esa plancha que están haciendo, les voy a decir por qué, porque en cuanto ellos tomaron el proceso y se quedaron allá, inmediatamente comenzaron a formar grupos y los que somos neófitos en el proceso, ¿para dónde cogemos? Mire, yo propongo que cada uno se organice, que den el espacio ahí, esta propuesta yo la estoy presentando en base a nuestras comunidades y entonces podamos hacer la elección, aquí hay gente que no sabe pa'ónde coger. ${ }^{20}$ 
Esta misma inquietud fue expresada por las delegadas, quienes además de señalar el carácter excluyente de las planchas, las calificaron como un mecanismo poco democrático que negaba la posibilidad de conocer las propuestas de los postulantes y, por tanto, de efectuar una votación transparente e informada. Las funcionarias también expresaron su inconformismo con la postulación de algunos de los delegados salientes para integrar las nuevas listas -opinión que, como se indicó, fue expresada por algunos asistentes cuyos reclamos no tuvieron ninguna repercusión, pues finalmente estos delegados resultaron electos-.

Estos cuestionamientos al proceso de elección de los delegados se vieron avivados por la ocurrencia de una situación inesperada. Cuando la asamblea se encontraba cerca de su finalización, una funcionaria se nos acercó para manifestarnos su indignación frente al hecho de que los integrantes de una de las planchas hubieran contratado un bus para transportar a un grupo de personas al lugar de la asamblea, buscando aumentar la votación a su favor y ofreciendo como contraprestación el almuerzo que estaba contemplado para los asistentes al evento. Bastante alterada, la funcionaria manifestó: "Esa gente, por un plato de comida, a dañar las cosas, es el colmo, yo creo que los llamaban a decirles 'venite como estés, en short, en bermudas, pero venite’, ¡las cosas no son así!”. El recurso al acarreo de votos, la favorabilidad hacia el sistema de planchas, así como la reelección de algunos de los delegados suscitaron una reflexión entre mis interlocutoras acerca de la manera en que los afrodescendientes terminan replicando el "modelo politiquero rancio de siempre", en palabras de una de ellas. A estos tres eventos podríamos agregar la solvencia con la que los asistentes a la asamblea utilizaban el lenguaje político electoral ( $v$. gr. plancha, voto nominal, cociente electoral, vicios de procedimiento), que integraban a su discurso con bastante naturalidad.

Diversos estudios señalan que la historia política de las regiones habitadas mayoritariamente por afrocolombianos ha estado signada por el sistema clientelista que ha encontrado en la precariedad económica de estas poblaciones, así como en las formas de organización social sustentadas en la familia extensa, el caldo de cultivo ideal para erigirse. El clientelismo político no solo ha llegado a convertirse en uno de los principales mecanismos de articulación de estas regiones a los circuitos de poder nacional, sino que además se constituye en una de las vías privilegiadas de ascenso y movilidad social, mediante el intercambio de bienes materiales y de favores por votos (Agudelo 2005; Castillo 2016; Grueso 2000; Hoffmann 2007; Wabgou et al. 2012). Para una población que ha sido socializada dentro de una cultura política en la que priman la lealtad hacia los partidos tradicionales y el ejercicio de prácticas clientelistas, resulta difícil escapar de estas 
formas de sociabilidad política, tal y como lo expresara una de las delegadas: "usted sabe que lo que uno conoce es lo que uno hace”. Ahora bien, las intervenciones de algunos de los asistentes a la asamblea parecen indicar que este punto de vista no es exclusivo de los funcionarios. Así lo evidencian las palabras de una lideresa:

Bueno, compañeros, yo sí quiero hacer un llamado de atención a la cordura y a la discusión y lo que les quiero decir es lo siguiente: nos quejamos de que estamos en la segregación y en la exclusión y repetimos modelos, y lo que está pasando aquí no es digno de llamarse democracia. Yo creo que el ejercicio tiene que ser un ejercicio transparente donde todos y cada uno, los que llegamos a este espacio a elegir y a ser elegidos, tengamos la posibilidad de hacer ese ejercicio. ${ }^{21}$

La apelación al proceso de esclavización del que fue objeto la población africana trasladada a América también hace parte de la narrativa política de los afrocolombianos. Esta evocación, que es frecuente en los distintos escenarios públicos en los que participan, no ha estado ausente en la mesa ni lo estuvo en la asamblea donde algunos líderes aludieron al secuestro del que fueron víctimas sus antepasados, así como a la gesta libertaria protagonizada por los cimarrones en contra de la esclavitud. De nuevo, estos discursos fueron puestos en cuestión por las delegadas, especialmente una que argumentó que no solo hacen parte del pasado, sino que además se han convertido en una estrategia de victimización por parte de sus congéneres:

Ese discurso de la esclavitud se lo regalo, no se lo vendo siquiera, sino que se lo regalo. El hecho de que por ser negros me tienen que dar todo gratis. La gente no puede pasar por el solo hecho del color y debe dejar esa actitud de estar mendigando. No se puede seguir en esa actitud de "pobrecito yo”, “a mí todo me lo tienen que dar”, ¡hay que avanzar!22

La misma funcionaria cuestionaba la invocación que algunos líderes hacen de su ascendencia de tribus africanas belicosas, como una manera de justificar actitudes intolerantes y beligerantes en los escenarios de debate público.

En el recuento anterior se han visto las construcciones discursivas que un grupo de funcionarias elabora en torno a las formas de ejercicio de lo político entre los afrodescendientes, cuyas prácticas son evaluadas en relación con los principios de transparencia, inclusión y defensa del interés colectivo que, a su entender, tendrían que orientar un proceso de elecciones democrático digno noviembre del 2016. 
de llamarse así. Estos discursos ponen en juego todo un sistema de valores a partir del cual se jerarquiza y categoriza a estas poblaciones, de acuerdo con ciertos principios binarios de clasificación: afrocolombianos/indígenas, orden/ desorden, disciplina/indisciplina, cohesión/fragmentación, autovictimización / capacidad de agencia, entre otros. Ahora bien, aunque en términos generales las funcionarias comparten una mirada crítica de las prácticas políticas de los afrodescendientes, es preciso señalar que sus posicionamientos frente a ellos varían en función de su pertenencia étnica. Así, en sus apreciaciones sobre los distintos episodios presentados en la asamblea, las delegadas mestizas adoptan cierta distancia que denota una frontera social entre un "nosotros” y un “ellos”, mientras que las delegatarias afrocolombianas asumen estas debilidades como propias en virtud de su pertenencia a este grupo étnico. Ello nos remite a la noción de intimidad cultural acuñada por Herzfeld ([1997] 2005) para explicar el conocimiento compartido por los miembros de un grupo que se reconocen entre sí a través de sus fallas e imperfecciones, aun a sabiendas de que estas son desaprobadas por quienes no pertenecen al grupo. Esta camaradería de la imperfección, que según el autor garantiza la sociabilidad entre los integrantes de una colectividad, permite comprender el esfuerzo que nuestras interlocutoras afrodescendientes hacen por entender el comportamiento de sus congéneres, como también por disociar la explicación de ciertas conductas ( $v$. gr. abuso de autoridad, corrupción, clientelismo) del color de la piel.

\section{A manera de conclusión}

En esta reflexión sobre el proceso de formulación de la política pública dirigida a las poblaciones afrodescendientes que residen en la ciudad de Cali, se ha intentado dar cuenta de la multiplicidad de actores, prácticas y discursos que intervienen en el complejo mundo de las políticas de la diferencia. En un sentido amplio, las políticas públicas pueden ser consideradas una ventana analítica que permite asomarse a la manera en que el Estado se materializa en el diario vivir de los individuos. El caudal de relaciones e intereses que ellas promueven es una oportunidad única para aproximarse a los procesos de negociación de la dominación que se producen, en distintos niveles y escalas, entre actores situados diferencialmente. En este caso particular, la observación de las interacciones entre las burocracias y los ciudadanos representados en los delegados de las organizaciones dejó al descubierto el modo en que se multiplican los efectos de la 
dominación estatal a través de la naturalización de los lenguajes y las prácticas de la estatalidad por parte de los sujetos, aun de aquellos que afirman oponerse al orden oficial. Pienso concretamente en los líderes que apelan a la normatividad estatal o exigen la presencia de los funcionarios titulares de los cargos en las reuniones de la Mesa Central de Concertación.

Este escenario también permitió aproximarse a la vida discursiva del Estado, es decir, al conjunto de imaginarios y representaciones que los individuos construyen en torno a este: los funcionarios ofreciendo interpretaciones autorizadas sobre los programas y políticas estatales y los voceros de las organizaciones tejiendo toda suerte de "teorías conspiratorias" para explicar sus tropiezos en la interacción con las entidades públicas. Ya sea como "guardianes del sistema” o como detractores del orden oficial, unos y otros participan en la construcción del Estado como una realidad social cotidiana. Al decir de Herzfeld ([1997] 2005), a través de estos pequeños actos de esencialización los actores contribuyen a hacer del Estado una presencia permanente en sus vidas, de tal suerte que muy pocos son capaces de manejarse completamente sin él. Ahora bien, estas fronteras entre funcionarios y líderes no son tan claras si se tiene en cuenta que una buena parte de los delegados institucionales son afrocolombianos, lo que, además de afectar la manera en que estos se relacionan con las poblaciones objetivo de las políticas, demuestra la permeabilidad de los límites que suelen establecerse entre la sociedad civil y el Estado.

Por otra parte, siguiendo la agenda de investigación propuesta por los antropólogos de las políticas públicas que señalan la importancia de abordar las creencias y actitudes que los profesionales y planificadores buscan sostener a partir de la formulación de las políticas, esta indagación se dirigió a esclarecer las construcciones discursivas de los funcionarios en torno a las poblaciones con las que desarrollan su trabajo. La etnografía realizada en la asamblea para la elección de los delegados a la mesa permitió aproximarse a los valores y principios éticos subyacentes a las interpretaciones de un grupo de funcionarias sobre el quehacer político de los líderes afrodescendientes, quienes, sin siquiera sospecharlo, entran a formar parte del complejo ejercicio de taxonomización inherente a la labor burocrática. 


\section{Referencias}

Abrams, Philip. 1988. "Notes on the Difficulty of Studying the State”. Journal of Historical Sociology 1 (1): 58-89. https://doi.org/10.1111/j.1467-6443.1988.tb00004.x.

Acuerdo 0234 del 2008. "Por medio del cual se establecen los criterios para la formulación e implementación de la Política Pública para la Población Afrocolombiana residente en el municipio de Santiago de Cali”. Concejo Municipal de Santiago de Cali.

Acuerdo 0237 del 2008. "Por medio del cual se adopta el Plan de Desarrollo del Municipio de Santiago de Cali 2008-2011 'Para vivir la vida dignamente”. Concejo Municipal de Santiago de Cali.

Agudelo, Carlos Efrén. 2005. Retos del multiculturalismo en Colombia. Política y poblaciones negras. Medellín: La Carreta.

Aretxaga, Begoña. 2003. “Maddening States”. Annual Review of Anthropology 32: 393-410. https://doi.org/10.1146/annurev.anthro.32.061002.093341.

Asher, Kiran. (2009) 2016. Negro y verde. Etnicidad, economía y ecología en los movimientos negros del Pacífico colombiano. Bogotá: ICANH; Universidad Icesi.

Bolívar, Ingrid. 2006. “Transformaciones de la política: movilización social, atribución causal y configuración del Estado en el Magdalena Medio”. En Conflictos, poderes e identidades en el Magdalena Medio, 1990-2001, editado por Mauricio Archila e Ingrid Bolívar, 375-464. Bogotá: Colciencias; Cinep.

— . 2010. “Formación del Estado y biografía de las categorías”. Nómadas 33: 93-108.

Bourdieu, Pierre. 1993. "Los ritos como actos de institución”. En Honor y gracia, editado por Julian Pitt-Rivers y John Peristiany, 111-123. Madrid: Alianza.

- .1994. "Rethinking the State: Genesis and Structure of the Bureaucratic Field". Sociological Theory 12 (1): 1-18.

— . 2014. Sobre el Estado. Cursos en el Collège de France (1989-1992). Barcelona: Anagrama.

Canelo, Brenda. 2008. "Dirigentes de migrantes andinos, empleados y funcionarios públicos ante 'el Estado'. Una mirada desde abajo para comprender procesos políticos locales (Ciudad de Buenos Aires, Argentina)”. Cuadernos de Antropología Social 27: 175-193.

Castillo, Luis Carlos. 2016. Organizaciones afrocolombianas: una aproximación sociológica. Cali: Universidad del Valle.

Centro de Investigaciones y Documentación Socioeconómica (Cidse). ACDI VOCA. 2016. Desigualdades étnico-raciales en las oportunidades de vida en Cali. Investigación y propuesta de política. Bogotá: USAID; Universidad del Valle; Cidse; Ministerio de Trabajo de Colombia; ACDI VOCA.

Chaves, Margarita y Juan Felipe Hoyos. 2011. "El estado en las márgenes y las márgenes como estado. Transferencias económicas y gobiernos indígenas en Putumayo”. En La multiculturalidad estatalizada: indígenas, afrodescendientes y configuraciones de estado, compilado por Margarita Chaves, 115-134. Bogotá: ICANH. 
Comisión Económica para América Latina y el Caribe (Cepal), Organización Panamericana de la Salud (OPS) y Fondo de Población de las Naciones Unidas (UNFPA). 2017. Situación de las personas afrodescendientes en América Latina y desafíos de políticas para la garantía de sus derechos. Santiago de Chile: Naciones Unidas. Consultado el 15 de febrero de 2018. http://repositorio.cepal.org/bitstream/handle/11362/42654/1/S1701063_es.pdf.

Consejo Nacional de Política Económica y Social. 1997. Documento Conpes 2909. "Programa de apoyo para el desarrollo y reconocimiento étnico de las comunidades negras”. Consultado el 10 de agosto del 2017. http://observatorioirsb.org/cmsAdmin/uploads/conpes2909.pdf.

— . 2002. Documento Conpes 3169. "Política para la población afrocolombiana”. Consultado el 10 de agosto del 2017. https://www.minagricultura.gov.co/Normatividad/Conpes/Conpes\%203169\%20de\%202012.pdf.

— . 2004. Documento Conpes 3310. "Política de acción afirmativa para la población negra o afrocolombiana”. Consultado el 10 de agosto del 2017. https://colaboracion.dnp.gov.co/CDT/ CONPES/Económicos/3310.pdf.

— . 2010. Documento Conpes 3660. "Política para promover la igualdad de oportunidades para la población negra, afrocolombiana, palenquera y raizal”. Consultado el 10 de agosto de 2017. http://convergenciacnoa.org/wp-content/uploads/2017/07/CONPES-3660.pdf.

Decreto 0634 del 2007. "Por medio del cual se crea la Mesa Central de Concertación de la Política Pública para la Población Afrodescendiente del Municipio de Santiago de Cali y se dictan otras disposiciones”. Alcaldía Municipal de Santiago de Cali.

Departamento Administrativo Nacional de Estadística (DANE). 2005. Censo General 2005. Consultado el 3 de febrero del 2017. http://www.dane.gov.co/index.php/esp/poblacion-yregistros-vitales/censos/censo-2005.

Fassin, Didier. 2015. "Introduction: Governing Precarity”. En At the Heart of the State. The Moral World of Institutions, editado por Didier Fassin, 1-11. Londres: Pluto Press.

Grueso, Libia. 2000. "El proceso organizativo de comunidades negras en el Pacífico sur colombiano”. Tesis de Maestría en Estudios Políticos, Facultad de Humanidades y Ciencias Sociales, Pontificia Universidad Javeriana, Cali.

Gupta, Akhil. 1995. "Blurred Boundaries: The Discourse of Corruption, the Culture of Politics, and the Imagined State”. American Ethnologist 22 (2): 375-402.

Gupta, Akhil y Aradhana Sharma. 2006. "Introduction: Rethinking Theories of the State in an Age of Globalization”. En The Anthropology of the State. A Reader, editado por Akhil Gupta y Aradhana Sharma, 1-42. Oxford: Blackwell Publishing.

Handelman, Don. 1981. "Introduction: The Idea of Bureaucratic Organization”. Social Analysis: The International Journal of Social and Cultural Practice 9: 5-23.

Hansen, Thomas Blom y Finn Stepputat. 2001. “Introduction: States of Imagination”. En States of Imagination: Ethnographic Explorations of the Postcolonial State, editado por Thomas Blom Hansen y Finn Stepputat, 1-38. Durham y Londres: Duke University Press.

Herron, James. 2003. "Animating the State: Discourses of Authority and Intimacy in the Colombian Agrarian Bank”. Tesis doctoral, Universidad de Michigan, Ann Arbor. 
Herzfeld, Michael. (1997) 2005. Cultural Intimacy. Social Poetics in the Nation-State. Nueva York; Londres: Routledge.

Heyman, Josiah. 2004. "The Anthropology of Power-Wielding Bureaucracies". Human Organization 63 (4): 487-500. https://doi.org/10.17730/humo.63.4.m9phulu49a112dep.

Hoffmann, Odile. 2007. Comunidades negras en el Pacífico colombiano. Innovaciones y dinámicas étnicas. Quito: Abya Yala; IFEA; IRD; Cemca; Ciesas.

Lagos, María. 2008. "Vida cotidiana, ciudadanía y el género de la política”. Cuadernos de Antropología Social 27: 91-112.

Lazar, Sian. 2008. "Eso es luchar sindicalmente. Ciudadanía, el Estado y los sindicatos en El Alto, Bolivia”. Cuadernos de Antropología Social 27: 63-90.

Martínez, Sandra. 2015. "Funcionarios y colonos: la formación del Estado en el suroriente colombiano”. Íconos. Revista de Ciencias Sociales 52: 79-98.

Murray Li, Tania. 2007. The Will to Improve. Governmentality, Development and the Practice of Politics. Durham; Londres: Duke University Press.

Nuijten, Monique. 2003. Power, Community, and the State. The Political Anthropology of Organisation in México. Londres: Pluto Press.

Pérez, Luis. 2002. "Desplazamiento forzado en Colombia 1995-1999: una aproximación empírica a las relaciones entre desplazamiento, conflicto armado y desarrollo”. En $E l$ desplazamiento forzado en Colombia: compromisos desde la universidad, 17-87. Bogotá: OIM; Ascun; Red de Solidaridad Social; AFS; Codhes; Usaid; Universidad Nacional de Colombia.

Programa de las Naciones Unidas para el Desarrollo (PNUD). 2010. "Políticas públicas para el avance de la población afrocolombiana: revisión y análisis”. Consultado el 28 de enero del 2017. https:/groups.google.com/forum/\#!topic/plan-integral-largo-plazo/ b071V5pe4GA.

Ramírez, María Clemencia. 2001. Entre el Estado y la guerrilla: identidad y ciudadanía en el movimiento de los campesinos cocaleros del Putumayo. Bogotá: ICANH; Colciencias.

Roseberry, William. 1994. "Hegemony and the Language of Contention”. En Everyday Forms of State Formation: Revolution and the Negotiation of Rule in Modern Mexico, editado por Gilbert Joseph y Daniel Nugent, 355-366. Durham: Duke University Press.

Shore, Cris. 2010. "La antropología y el estudio de la política pública: reflexiones sobre la ‘formulación' de las políticas”. Antípoda 10: 21-49.

Shore, Cris y Susan Wright. 1997. "Policy: A New Field of Anthropology”. En The Anthropology of Policy: Critical Perspectives on Governance and Power, editado por Cris Shore y Susan Wright, 3-39. Nueva York: Routledge.

Torres, María Clara. 2006. “Formas de pensar y experimentar ‘la política’ y ‘el Estado’ en lo local: la creación del municipio de San Miguel en Putumayo”. En Globalización, cultura y poder en Colombia: una mirada interdisciplinar, compilado por Fernán González y Gloria Isabel Ocampo, 171-184. Medellín: Universidad de Antioquia; Colciencias.

— . 2007. “Comunidades y coca en el Putumayo: prácticas que hacen aparecer al Estado”. Controversia 188: 199-245. 
Trouillot, Michel-Rolph. 2001. "The Anthropology of the State in the Age of Globalization: Close Encounters of the Deceptive Kind”. Current Anthropology 42 (1): 125-138.

Wabgou, Maguemati, Jaime Arocha, Aidén Salgado y Juan Carabalí. 2012. Movimiento social afrocolombiano, negro, raizal y palenquero. El largo camino hacia la construcción de espacios comunes y alianzas estratégicas para la incidencia política en Colombia. Bogotá: Universidad Nacional de Colombia.

Wade, Peter. 1997. Gente negra, nación mestiza: dinámicas de las identidades raciales en Colombia. Bogotá: Siglo del Hombre; Ediciones Uniandes.

Weber, Max. (1922) 1977. Economíay sociedad. Ciudad de México: Fondo de Cultura Económica.

Wedel, Janine, Cris Shore, Gregory Feldman y Stacy Lathrop. 2005. “Towards an Anthropology of Public Policy”. The Annals of the American Academy of Political and Social Sciences 600: 30-51. 